\title{
Fundamental factors related to orthodontic micro-implant stability: Review of the literature
}

\section{Najważniejsze czynniki związane ze stabilizacją mikroimplantów ortodontycznych - przegląd piśmiennictwa}

\author{
Jan Łyczek $^{A-F}$, Joanna Antoszewska-Smith ${ }^{A-F}$ \\ Department of Orthodontics and Dentofacial Orthopedics, Wroclaw Medical University, Wrocław, Poland \\ A - research concept and design; $\mathrm{B}$ - collection and/or assembly of data; $\mathrm{C}$ - data analysis and interpretation; \\ $D$ - writing the article; $E$ - critical revision of the article; $F$ - final approval of article
}

Address for correspondence

Jan Łyczek

E-mail:jan.lyczek@gmail.com

Funding sources

none declared

Conflict of interest

none declared

Received on January 26, 2017

Revised on March 3, 2017

Accepted on April 12, 2017

\begin{abstract}
The development and introduction of temporary intraoral anchorage devices (TISAD) in the beginning of the $21^{15 t}$ century had a great impact on contemporary orthodontics. The enhancement of the scope of orthodontic treatment, improved efficiency, reduction of both the treatment time and need for the patient's compliance, all of these are the crucial advantages the TISAD have provided to our profession. However, there are also some limiting factors pertaining to this anchorage reinforcement technique which must be borne in mind prior to clinical application. Among some others, premature failure of the micro-implants is the most significant problem related to their utilization, as it entails a repetition of the insertion procedure, increasing the cost and duration of treatment and causing the patient's discomfort. Therefore, recognition of the factors related to the stability of orthodontic micro-implants is necessary for their efficient clinical application and maximum survival rates. Since over the last decade there has been noteworthy progress in the research investigating the issue of micro-implant stability, a review of the most current literature pertaining to this topic was the aim of our article, and ultimately providing clinical recommendations.
\end{abstract}

Key words: stability, micro-implants, success rates, micro-screws, TAD

Słowa kluczowe: stabilność, mikroimplanty, współczynniki sukcesu, mikrośruby, TAD

DOI

$10.17219 / \mathrm{dmp} / 70440$

Copyright

() 2017 by Wroclaw Medical University

and Polish Dental Society

This is an article distributed under the terms of the

Creative Commons Attribution Non-Commercial License

(http://creativecommons.org/licenses/by-nc-nd/4.0/) 
Temporary intraoral anchorage devices (TISAD) constitute a group of modern anchorage reinforcement tools which share a unique feature: the ability to provide absolute and compliance-free anchorage. The development of TISAD at the beginning of $21^{\text {st }}$ century has noticeably extended orthodontic treatment efficacy along with the improvement of the patient's comfort. Nevertheless, as any other anchorage bolstering technique, use of TISAD bears some drawbacks, where loss of stability is the major one. Reported micro-implant success rates range from 75 to $94 \%$, therefore roughly from 1 to 3 out of 10 inserted TISAD become mobile and cannot serve according to intent. $^{1-4}$ As a consequence, the failure of a micro-screw requires another implantation, increasing treatment cost, time and discomfort. Premature loss of orthodontic micro-implants has been a fundamental problem since their introduction to clinical practice, constantly calling for identification of the determinants favoring TISAD instability. The literature from the last decade deals with this issue substantially, thus the aim of this article was an evidence-based appraisal of the most crucial factors related to micro-implant survival, taking into account the most recent scientific findings. A search of the Medline, Scopus, Ebsco and Web of Science electronic databases was performed with all combinations of the key words: micro-implants, mini-implants, micro-screws, mini-screws, TAD and TISAD, and stability, success rate and risk factor. After reviewing the articles published from 2000 to 2016, we have summarized the most important findings in this paper. The determinants discussed were divided into 3 categories encompassing: the properties of a micro-implant, the patient's characteristics and management of TISAD.

\section{Design of a micro-implant}

Table 1 summarizes the influence of the orthodontic micro-implant design on its stability. Micro-implants have the shape of a screw with a diameter $1.0-2.0 \mathrm{~mm}$ and a length 6-12 $\mathrm{mm}$. The small dimensions are essential since they make possible TISAD placement in narrow interradicular spaces, thus providing an appropriate orthodontic force vector. However, it must be borne in mind that TISAD stabilization depends mostly on their primary stability, thus - theoretically - larger sizes, as opposed to smaller ones, will promote firmness of the micro-screws and there are reports in the literature indeed confirming such thesis. Miyawaki et al. ${ }^{5}$ and Motoyoshi et al. ${ }^{6}$ suggest that screws with a diameter equal to or smaller than $1.0 \mathrm{~mm}$ should be avoided, because their failure rate is significantly higher comparing to the screws with larger cross-section areas. The study of Wilmes et al. ${ }^{7}$ supported this result, as the authors similarly found $1.1 \mathrm{~mm}$ screw stability fairly lower than $1.6 \mathrm{~mm}$ ones. In turn, Chen et al. ${ }^{8}$ and Sarul et al. ${ }^{9}$, while investigating the impact of micro-implant length, concordantly reported that screws
$8 \mathrm{~mm}$ long are more stable than $6 \mathrm{~mm}$ ones. Last but not least, two independent meta-analyses by Crismani et al. ${ }^{10}$ and Dalessandri et al. ${ }^{11}$ have validated these outcomes and stated that sizes of minimum $1.2 \times 8 \mathrm{~mm}$ and $1.3 \times 8 \mathrm{~mm}$, respectively, ensure sufficient primary stability of micro-screws. Therefore, micro-implants with at least such dimensions are advocated for most clinical applications, with exceptional use of the smaller TISAD in carefully selected cases.

As for the TISAD design, Migliorati et al. studied the micro-screw thread shape influence on stability. ${ }^{12}$ They evaluated a geometrical TISAD relationship to describe the mechanical properties of miniscrews, calculated as the relationship between the mean thread depth and the pitch $(\mathrm{D} / \mathrm{P})$, expressed as a percentage. The authors proved that a higher percentage significantly correlates with better micro-implant stability. Chadad et al. also proved that etching and sandblasting the micro-implant's surface does not increase its stability, which again underscores the crucial role of the screw size. ${ }^{13}$

\section{Patient's characteristics}

\section{Sex and age}

A summary of the patient's characteristics' impact on the stability of micro-implants is presented in Table 2. Most of the researchers did not find significant differences between men and women in terms of micro-implant stability ${ }^{14-18}$, which was entirely supported in 2 independent meta-analyses ${ }^{10,11}$ evidently proving that sex does not affect micro-implant loosening.

In regard to age, Chen et al. ${ }^{16}$ observed significantly more frequent micro-screw instability in 20 to 30 year-old patients, contrary to Lee et al. ${ }^{17}$ who noted the highest success rates in such individuals. Apart from these 2 reports, the majority of the studies did not reveal any relationship of micro-implant stability and the patient's age; $4,5,14,15$ again: 2 meta-analyses endorse such outcomes. ${ }^{10,11}$ And although Dalessandri et al. ${ }^{11}$ indicate a higher failure rate in patients under 20 years of age, the difference is minor and insignificant.

Table 1. Influence of micro-implant design on its stability

\begin{tabular}{|c|c|}
\hline $\begin{array}{l}\text { Micro-implant } \\
\text { design }\end{array}$ & $\begin{array}{l}\text { Influence on the stability } \\
\text { of the micro-implant }\end{array}$ \\
\hline Diameter & $\begin{array}{l}\text { diameter of at least } 1-2 \mathrm{~mm} \text { improves } \\
\text { the stability of micro-implants }\end{array}$ \\
\hline Length & $\begin{array}{l}\text { length of at least } 8 \mathrm{~mm} \text { promotes } \\
\text { the stability of micro-implants }\end{array}$ \\
\hline Thread shape factor & $\begin{array}{l}\text { higher values of thread shape factor increase } \\
\text { the stability of micro-implants }\end{array}$ \\
\hline Surface preparation & $\begin{array}{l}\text { etching and sandblasting does not enhance } \\
\text { the stability of micro-implants }\end{array}$ \\
\hline
\end{tabular}




\section{Bone anatomy and histology}

Micro-implants installed in the mandible have been reported to fail significantly more often than those placed in the maxilla. ${ }^{14-18}$ Cheng et al. has suggested that the thick cortical plate in the mandible conduces to a rapid raise of the temperature during hole drilling, which may result in bone overheating. ${ }^{15}$ Another issue resulting from greater cortical thickness is a risk of ischemia of the bone due to the high pressure exerted by the micro-implant. ${ }^{19}$ Both the high temperature and high pressure result in necrosis and degeneration of the bone supporting the micro-implant, which subsequently loses primary stability and requires replacement. On the other hand, there are some studies that did not reveal any differences in micro-implant stability in the maxilla or the mandible. Chen et al. ${ }^{20}$ stated that the quality of the bone itself rather than location is paramount for micro-screw fixation, which is in accordance with the studies published by Miyawaki et al. ${ }^{5}$, who similarly concluded that cortical thickness overrides the issue of location itself. Nevertheless, the results of the meta-analyses clearly indicate that orthodontic micro-implants placed in the mandible have a higher risk of failure. ${ }^{10,11}$ Thus, already at the stage of treatment planning, one needs to consider another anchorage reinforcement method, applicable when loosening of the TISAD in the mandible emerges.

The role of bone quality and quantity in achieving primary stability, so crucial for micro-screw survival, seems quite obvious. The ability to hold the screw in the bone is defined by parameters such as: 1. tightening torque and 2. pull out force. Experimental studies have revealed a positive correlation between these two variables and the thickness and density of the cortical plate and density of the cancellous bone, ${ }^{21-24}$ further supported by the results of research on human cadavers. ${ }^{25}$ Motoyoshi et al. have established that the critical thickness ensuring sufficient primary stability is $1 \mathrm{~mm} .{ }^{26}$ The results of the meta-analysis conducted by Marquezan et al. ${ }^{27}$ confirmed a positive correlation between cortical bone thickness and the sta-

Table 2. Influence of patient characteristics on the stability of micro-implants

\begin{tabular}{|c|c|}
\hline Factor & $\begin{array}{l}\text { Influence on the stability } \\
\text { of the micro-implant }\end{array}$ \\
\hline Sex & $\begin{array}{l}\text { sex has no influence on the stability } \\
\text { of micro-implants }\end{array}$ \\
\hline Age & $\begin{array}{c}\text { age has no or very little impact on the stability } \\
\text { of micro-implants }\end{array}$ \\
\hline Location & $\begin{array}{l}\text { micro-implants are more stable in maxilla } \\
\text { compared to mandible }\end{array}$ \\
\hline $\begin{array}{l}\text { Bone quality and } \\
\text { quantity }\end{array}$ & $\begin{array}{c}\text { thicker cortical plate and higher bone density } \\
\text { promote stability of the micro-implants }\end{array}$ \\
\hline Placement torque & $\begin{array}{l}\text { values ranging from } 5 \text { to } 10 \mathrm{~N} / \mathrm{cm} \text { correlate } \\
\text { with higher stability of the micro-implants }\end{array}$ \\
\hline Nicotine addiction & $\begin{array}{l}\text { smoking of } 10 \text { or more cigarettes a day impairs } \\
\text { the stability of micro-implants }\end{array}$ \\
\hline
\end{tabular}

bility of micro-implants, though the authors emphasized the need for more high-quality clinical studies to support the final conclusion. Motoyoshi et al. demonstrated that the optimal placement torque values lie in the limit from 5 to $10 \mathrm{~N} / \mathrm{cm}^{28}$ According to those authors, a lower number indicates insufficient mechanical fixation of the micro-screw, whereas a higher number reflects very strong pressure exerted by the implant on the bone, which may result in ischemic osteonecrosis. A meta-analysis by Meursinge Reynders et al. did not reveal any ideal micro-implant placement torque rate, however this may be partly caused by a very limited number of studies meeting the criteria and included in the analysis. ${ }^{29}$

\section{Susceptibility to inflammation}

The detrimental influence of the inflammatory process of tissues surrounding the micro-implants has been widely emphasized as well. 2,5,15,20,30-32 Experimental studies show that a penetrating inflammatory process results in degeneration of the bone supporting the micro-implant that finally loses its stability. ${ }^{32,33}$ Dalessandri et al. proved that peri-micro-implantitis entails an almost 9-fold increase of the risk of micro-screw failure and seems to be one of the most important factors responsible for this complication. ${ }^{11}$ The phenomena may develop as a consequence of infection from oral micro-flora or may be caused by proximity or tight contact with the adjacent root. ${ }^{34}$ Therefore, a fully aseptic and precise micro-implant placement procedure, along with meticulous hygiene of micro-screw surrounding tissues is paramount for a reduction of inflammation-related failures. As shown by Kuroda et al., the incidence of inflammations is higher when the micro-implant is placed in free mucosa, thus localization in attached gingiva is also recommended whenever applicable..$^{35}$

\section{Nicotine addiction}

Bayat and Baus showed that patients who smoke more than 10 cigarettes a day have a significantly higher risk of micro-implant failure than non-smokers or those who smoke less. ${ }^{36}$ Therefore, a medical questionnaire should help to investigate the presence and intensity of nicotinism and the number of cigarettes smoked, which - if severe or high - ought to be considered while estimating the potential stability of micro-screws applied in a given individual.

\section{Management of TISAD}

\section{Placement procedure}

The influence of micro-implant management on its stability is shown in Table 3. There are multiple surgical protocols of micro-implant placement reported in the lit- 
erature and the basic differentiation concerns pre-drilling (self-tapping) and drill-free (self-drilling) methods. ${ }^{30,37}$ Experimental studies on dogs showed higher stability of the micro-implants placed with the drill-free approach, and subsequent histological analysis revealed more tight contact between the screw and the surrounding bone. ${ }^{38}$ Similar results were obtained in clinical studies, which compared the success rates of $1.4 \mathrm{~mm}$ micro-implants placed in the self-tapping method with 0.9 or $1.1 \mathrm{~mm}$ pilot bur and without pre-drilling. ${ }^{39}$ Statistically significant differences in success rates were noted: the highest in case of micro-screws placed without pre-drilling and the lowest in case of TISAD inserted in a hole drilled with $1.1 \mathrm{~mm}$ bur. The results of the cited studies indicate that micro-implant placement without pre-drilling promotes stability, however these outcomes should be interpreted with caution due to the limited number of micro-screws analyzed. It seems that in the maxilla, due to thin cortical and thick cancellous bone, skipping the drilling may enhance the bone-screw contact and improve stability. On the other hand, in the presence of very thick cortical bone in the mandible, micro-implantation without pre-drilling entails a high risk of inducing excessive pressure on the bone, likely resulting in ischemia and necrosis, which is why pre-drilling is necessary in the mandible. Miyawaki et al..$^{5}$ and Kuroda et al..$^{35}$ compared the surgical protocols with and without muco-periosteal flap elevation and found a higher survival rate of micro-implants inserted using the flapless procedure. Furthermore, postoperative pain and swelling were also significantly lower in patients who received the less invasive, flapless surgery. ${ }^{35}$ Therefore, a small $(2-3 \mathrm{~mm})$ vertical stab incision of the mucosa, preceding TISAD insertion, which exposes the bone surface and prevents the soft tissues from winding around a pilot drill, seems to be the optimal soft tissue management, which is confirmed by Antoszewska et al., who utilized such protocol and obtained very high success rates, exceeding $93 \%{ }^{4}$

\section{Loading protocol}

In contrast to prosthetic implants, requiring a healing period lasting several months and the necessity for osteointegration, orthodontic micro-implants may be loaded much earlier because their fixation relies mostly on primary, not on secondary stability. Some osteointegration indeed occurs in the case of TISAD, however it does not play a major role in their immovability. ${ }^{40}$ The timing of the loading recommended in the literature ranges from immediate to 3 months post-operatively, although most of the authors deemed immediate loading possible and rational, provided a low force value is applied. ${ }^{2,5,38-42}$ The meta-analysis by Crismani et al. made it possible to determine the optimal conditions of loading the micro-implants: several days after placement with a force up to 200 g. ${ }^{10}$ Early loading is further validated by the meta-analysis of Dalessandri et al., who showed no
Table 3. Influence of micro-implant management on their stability

\begin{tabular}{|l|c|}
$\begin{array}{l}\text { Micro-implant } \\
\text { management }\end{array}$ & $\begin{array}{c}\text { Influence on the stability of the micro-implant } \\
\text { Self-drilling vs } \\
\text { Self-tapping }\end{array}$ \\
$\begin{array}{l}\text { in the maxilla: smaller or no pilot drilling promotes } \\
\text { in the mandible: pilot drilling with a bur-screw } \\
\text { difference of } 0.3-0.5 \mathrm{~mm} \text { indicated } \\
\text { flap preparation } \\
\text { flaps surgery ensures higher stability } \\
\text { of the micro-implants }\end{array}$ \\
Loading protocol & allowed immediate loading with forces up to $200 \mathrm{~g}$ \\
\hline
\end{tabular}

difference in stability between micro-implants loaded within or over 4 weeks after insertion. ${ }^{11}$ Nevertheless, it seems reasonable to postpone loading for 2 weeks after micro-implant placement, in order to allow uneventful healing of the mucosa around the TISAD heads, which is crucial to prevent inflammation: one of the major causes of micro-screw failures.

\section{Operator's experience}

Lim et al. demonstrated that the experience of the operator has a significant impact on the stability of micro-implants. ${ }^{37}$ The authors reported that clinicians who had inserted at least 20 micro-screws had a 3.6 times higher chance of achieving primary stability, compared to operators who had performed fewer procedures. ${ }^{37}$ Jung et al. proved that the clinician's experience also plays a role in placing the TISAD on the palate. ${ }^{43}$ What is more, Cho et al. found that the higher the number of performed micro-implantations, the lower the risk of damaging an adjacent root. ${ }^{44} \mathrm{~A}$ comparison of the stability of micro-implants inserted by a maxillofacial surgeon and an orthodontist showed no significant differences, indicating that orthodontists are fully capable of performing successful micro-implantations after they have gained the necessary experience. ${ }^{20}$

\section{Summary}

Temporary Intraoral Skeletal Anchorage Devices have gradually achieved widespread use in contemporary orthodontics; therefore awareness of the factors affecting the stability of the micro-implants is crucial for full utilization of the potential they offer. According to the most up-to-date research, bone quality and quantity, use of micro-screws of at least $1.2 \times 8 \mathrm{~mm}$ dimensions and prophylaxis of inflammation are fundamental for micro-implant survival, whereas unadaptable factors such as age and sex do not have a significant impact on micro-screw loosening, which to this day occurs more frequently in the mandible. Greater experience in the surgical procedure improves the stability of inserted micro-implants; hence it is necessary to improve the learning curve in order to maximize the success rates of the micro-screws. 


\section{References}

1. Baek SH, Kim BM, Kyung SH, Lim JK, Kim YH. Success rate and risk factors associated with mini-implants reinstalled in the maxilla. Angle Orthod. 2008;78:895-901.

2. Luzi C, Verna C, Melsen B. A prospective clinical investigation of the failure rate of immediately loaded mini-implants used for orthodontic anchorage. Prog Orthodont. 2007;8:192-201.

3. Wiechmann D, Meyer $U$, Büchter A. Success rate of mini- and micro-implants used for orthodontic anchor age: a prospective clinical study. Clin Oral Implan Res. 2007;18:263-267.

4. Antoszewska J, Papadopoulos MA, Park HS, Ludwig B. Five-year experience with orthodontic miniscrew implants: A retrospective investigation of factors influencing success rates. Am J Orthod Dentofacial Orthop. 2009;136:158.e1-10.

5. Miyawaki S, Koyama I, Inoue M, Mishima K, Sugahara T, Takano-Yamamoto T. Factors associated with the stability of titanium screws placed in the posterior region for orthodontic anchorage. Am J Orthod Dentofacial Orthop. 2003;124:373-378.

6. Motoyoshi M. Clinical indices for orthodontic mini-implants. J Oral Sci. 2011;53:407-412.

7. Wilmes B, Rademacher C, Olthoff G, Drescher D. Parameters affecting primary stability of orthodontic mini-implants. J Orofac Orthop. 2006;67:162-174.

8. Chen $\mathrm{CH}$, Chang $\mathrm{CS}$, Hsieh $\mathrm{CH}$, et al. The use of microimplants in orthodontic anchorage. J Oral Maxillofac Surg. 2006;64:1209-1213.

9. Sarul M, Minch L, Park HS, Antoszewska-Smith J. Effect of the length of orthodontic mini-screw implants on their long-term stability: A prospective study. Angle Orthod. 2015;85:33-38.

10. Crismani AG, Bertl MH, Celar AG, Bantleon HP, Burstone CJ. Miniscrews in orthodontic treatment: Review and analysis of published clinical trials. Am J Orthod Dentofacial Orthop. 2010;137:108-113.

11. Dalessandri D, Salgarello $S$, Dalessandri $M$, et al. Determinants for success rates of temporary anchorage devices in orthodontics: A meta-analysis ( $n>50$ ). Eur J Orthod. 2014;36:303-313.

12. Migliorati M, Benedicenti S, Signori A. Thread shape factor: evaluation of three different orthodontic miniscrews stability. Eur $J$ Orthod. 2013:35:401-405.

13. Chaddad K, Ferreira AF, Geurs N, Reddy MS. Influence of surface characteristics on survival rates of mini-implants. Angle Orthod. 2008;78:107-113.

14. Moon CH, Park HK, Nam JS, Im JS, Baek SH. Relationship between vertical skeletal pattern and success rate of orthodontic mini-implants. Am J Orthod Dentofacial Orthop. 2010;138:51-57.

15. Cheng SJ, Tseng IY, Lee, JJ, Kok SH. A prospective study of the risk factors associated with failure of mini-implants used for orthodontic anchorage. Int J Oral Maxillofac Implants. 2004;19:100-106.

16. Chen YJ, Chang HH, Huang CY, et al. A retrospective analysis of the failure rate of three different orthodontic skeletal anchorage systems. Clin Oral Implan Res. 2007;18:768-775.

17. Lee SJ, Ahn SJ, Lee JW, Kim SH, Kim TW. Survival analysis of orthodontic mini-implants. Am J Orthod Dentofacial Orthop. 2010;137:194-199.

18. Lim HJ, Eun CS, Cho JH, Lee KH, Hwang HS. Factors associated with initial stability of miniscrews for orthodontic treatment. Am J Orthod Dentofacial Orthop. 2009;136:236-242.

19. Meredith N. Assessment of implant stability as a prognostic determinant. Int J Prosthodont. 1998;11:491-501.

20. Chen YJ, Chang HH, Lin HY, et al. Stability of miniplates and miniscrews used for orthodontic anchorage: Experience with 492 temporary anchorage devices. Clin Oral Implan Res. 2008;19:1188-1196.

21. Çehreli S, Arman-Özçırpıcı A. Primary stability and histomorphometric bone-implant contact of self-drilling and self-tapping orthodontic microimplants. Am J Orthod Dentofacial Orthop. 2012;142:187-195.

22. Migliorati M, Benedicenti S, Signori A, et al. Thread shape factor: Evaluation of three different orthodontic miniscrews stability. Eur J Orthod. 2012;35:401-405.

23. Wilmes B, Drescher D. Impact of bone quality, implant type, and implantation site preparation on insertion torques of mini-implants used for orthodontic anchorage. Int J Oral Maxillofac Surg. 2011;40:697-703.
24. Cha JY, Kil JK, Yoon TM, Hwang CJ. Miniscrew stability evaluated with computerized tomography scanning. Am J Orthod Dentofacial Orthop. 2010;137:73-79.

25. McManus MM, Qian F, Grosland NM, Marshall SD, Southard TE. Effect of miniscrew placement torque on resistance to miniscrew movement under load. Am J Orthod Dentofacial Orthop. 2011;140:93-98.

26. Motoyoshi M, Yoshida T, Ono A, Shimizu N. Effect of cortical bone thickness and implant placement torque on stability of orthodontic mini implants. Int J Oral Maxillofac Implants. 2007;22:779-784.

27. Marquezan M, Trindade Mattos C, Franzotti Sant'Anna E, de Souza MM, Cople Maia L. Does cortical thickness influence the primary stability of miniscrews? A systematic review and meta-analysis. Angle Orthod. 2014;84:1093-1103.

28. Motoyoshi M, Hirabayashi M, Uemura M, Shimizu N. Recommended placement torque when tightening an orthodontic mini-implant. Clin Oral Implan Res. 2006;17:109-114.

29. Meursinge Reynders RA, Ladu L, van Etten-Jamaludin F, Bipat S. Insertion torque and success of orthodontic mini-implants: A systematic review. Am J Orthod Dentofacial Orthop. 2012;142:596-614.

30. Park HS, Jeong SH, Kwon OW. Factors affecting the clinical success of screw implants used as orthodontic anchorage. Am J Orthod Dentofacial Orthop. 2008;130:18-25.

31. Viwattanatipa N, Thanakitcharu S, Uttraravichien A, Pitiphat W. Survival analyses of surgical miniscrews as orthodontic anchorage. Am J Orthod Dentofacial Orthop. 2009;136: 29-36.

32. Zitzmann NU, Berglundh T, Ericsson I, Lindhe J. Spontaneous progression of experimentally induced peri-implantitis. J Clin Periodontol. 2004;31:845-849.

33. Ericsson I, Berglundh T, Marinello C, Liljenberg B, Lindhe J. Long-standing plaque and gingivitis at implants and teeth in the dog. Clin Oral Implan Res. 1992;3:99-103.

34. Kuroda S, Yamada K, Deguchi T, Hashimoto T, Kyung HM, Takano-Yamamoto T. Root proximity is a major factor for screw failure in orthodontic anchorage Am J Orthod Dentofacial Orthop. 2007;131:Suppl 4:68-73.

35. Kuroda S, Sugawara Y, Deguchi T, Kyung HM, Takano-Yamamoto T. Clinical use of miniscrew implants as orthodontic anchorage: success rates and postoperative discomfort. Am J Orthod Dentofacial Orthop. 2007;131:9-15.

36. Bayat $E$, Bauss $O$. Effect of smoking on the failure rates of orthodonticminiscrews. J Orofac Orthop. 2010;71:117-124.

37. Lim HJ, Choi YJ, Evans CA, Hwang HS. Predictors of initial stability of orthodontic miniscrew implants. Eur J Orthod. 2011;33:528-532.

38. Chen Y, Shin HI, Kyung HM. Biomechanical and histological comparison of self-drilling and self-tapping orthodontic microimplants in dogs. Am J Orthod Dentofacial Orthop. 2008; 133:44-50.

39. Türköz C, Ataç MS, Tuncer C, Balos Tuncer B, Kaan E. The effect of drill-free and drilling methods on the stability of mini-implants under early orthodontic loading in adolescent patients. Eur JOrthod. 2011;33:533-536.

40. Melsen B, Costa A. Immediate loading of implants used for orthodontic anchorage. Clin Orthod Res. 2000;3:23-28.

41. Büchter A, Wiechmann D, Koerdt S, Wiesmann HP, Piffko J, Meyer U. Load-related implant reaction of mini-implants used for orthodontic anchorage. Clin Oral Implan Res 2005;16:473-479.

42. Motoyoshi M, Matsuoka M, Shimizu N. Application of orthodontic mini-implants in adolescents. Int J Oral Maxillofac Surg. 2007;36:695-699.

43. Jung BA, Kunkel M, Göllner $P$, Liechti $T$, Wagner $W$, Wehrbein $H$. Prognostic parameters contributing to palatal implant failures: A long-term survival analysis of 239 patients. Clin Oral Implan Res. 2012;23:746-750.

44. Cho UH, Yu W, Kyung HM. Root contact during drilling for microimplant placement. Affect of surgery site and operator expertise. Angle Orthod. 2010;80:130-136. 
